\title{
DISCUTIENDO CON UN CREYENTE EN LA “NECESIDAD” DE “FUNDAMENTAR” LOS DERECHOS HUMANOS
}

\author{
DISCUSSING AGAINST A BELIEVER IN THE “NEED” T0 \\ HAVE THEORETICAL “FOUNDATIONS” FOR HUMAN \\ RIGHTS
}

\author{
ENRIQUE P. HABA*
}

Recibido: 03/08/2018

Aceptado: 25/09/2018

SUMARIO: I. FALACIOSIDAD DE ABOCARSE A “FUNDAMENTAR” LOS DD.HH.: GENERALIDADES. II. PLANTEAMIENTO GENERAL DE LA TESIS ACADEMICISTA: SUPUESTA “NECESIDAD” DE "FUNDAMENTAR” LOS DD.HH. III. "RAZÓN" PRIMERA: ¿ES UNA CUESTIÓN DE “MORAL”? IV. "RAZÓN” SEGUNDA: ¿ES UNA CUESTIÓN DE “LÓGICA”? V. “RAZÓN” TERCERA: ARGUMENTO “TEÓRICO”. VI. “RAZÓN” CUARTA: ARGUMENTO “PRAGMÁTICO”. VII... PERO, ¿QUÉ SIGNIFICA AHÍ “FUNDAMENTAR”? (FALACIAS BÁSICAS). VIII. EN CONCLUSIÓN: FÓRMULAS VACÍAS, CUESTIONES DE PALABRAS Y DEMÁS. IX. LITERATURA.

SUMMARY; I. THE FALLACY OF SEARCHING FOR ANY “FOUNDATIONS” OF HUMAN RIGHTS: OVERVIEW. II. GENERAL PRESENTATION OF SUCH ACADEMICIST THESIS: THE ALLEGED "NEED" TO FURNISH SOME THEORETICAL "FOUNDATION" FOR HUMAN RIGHTS. III. FIRST "REASON": IS THAT A MATTER OF "MORALS"? IV. SECOND "REASON": IS THAT A MATTER OF “LOGIC”? V. THIRD "REASON”: THE “THEORETICAL” ARGUMENT. VI: FOURTH “REASON”: THE “PRAGMATIC” ARGUMENT. VII. ...BUT THERE, WHAT DOES IT MEAN TO HAVE A THEORETICAL “FOUNDATION”? (THE BASIC FALLACIES). VIII. IN CONCLUSION: EMPTY FORMULAE, QUESTIONS OF WORDS, AND OTHER SUCH THINGS. IX. BIBLIOGRAPHY.

Resumen: La elucidación de “fundamentos” para lo que se llama "derechos humanos” no tiene repercusiones si no es en discursividades académico-celestiales, o unas menciones sobre aquella constituyen un eventual parapeto retórico cuando se resuelve sobre tales derechos en el ámbito judicial, o simplemente forman parte en actividades de orden ceremonial-internacional. Esta tesis se confronta aquí con cuatro órdenes de "razones" por las cuales se da en imaginar que existiría una "necesidad de fundamentar los derechos humanos".

Palabras claves: derechos fúmanos, fundamentos, (pseudo)razones, fórmulas vacías, falacia intelectualista, utilidad.

Abstract: Research consecrated to find out any "foundations" for the so-called "human rights" is misleading; it has no utility neither for real knowledge nor for social practice. Such "foundations" furnish matter for celestial discourses to accomplish some academic activities, or they provide a rhetorical parapet in judicial speeches, or are invoked in some ceremonies of the diplomatic world. This paper argues against four kinds of "reasons" which lead to imagine that "human rights need a foundation".

\footnotetext{
* Catedrático de la Universidad de Costa Rica. — e.p.haba.m@gmail.com // enrique.haba@ucr.ac.cr
}

https://dx.doi.org/10.17561/rej.n18.a3

Revista de Estudios Jurídicos n 18/2018 (Segunda Época)

ISSN-e 2340-5066. Universidad de Jaén (España)

Versión electrónica: rej.ujaen.es 
Enrique P. Haba

Keywords: human rights, foundations, pseudo-reasons, empty formulae, intellectualist fallacy, utility. 
El mito no posee fundamentos, no los necesita. Y no porque no pueda poseerlos, es al contrario: no puede poseer ninguno, porque no necesita ninguno.

Para la preservación de esos derechos no es tampoco muy importante proveerlos de unas pseudofundamentaciones, fácilmente refutables; mucho más fundamental es reconocer, y en lo posible conservar, el conjunto de las condiciones sociales bajo las que aquellos resultan posibles $y$ eficaces.

No sólo hay que defenderse de las soluciones, hay que defenderse hasta de las cuestiones, de los problemas mismos que se plantean en los enunciados ${ }^{1}$.

\section{FALACIOSIDAD DE ABOCARSE A “FUNDAMENTAR” LOS DD.HH.: GENERALIDADES}

Los contenidos de la señalización llamada "derechos humanos" (DD.HH.) se determinan convencionalmente, como en toda expresión lingüística. Son de orden histórico-voluntarista, variables en el tiempo y en el espacio. Esa "voluntad" no es, desde luego, la de una persona determinada o de algunas cuantas. Responde a sentimientos que espontáneamente se conforman en grupos humanos, motivados por tales o cuales circunstancias sociales habituales. Ello conforma entonces unas corrientes de opinión que tienen influencias en la colectividad considerada, muy generalizadas o particularmente para ciertos sectores de ella. Dichos sentimientos hacen que el membrete DD.HH. posea señalado sabor persuasivo de legitimación colectiva. Influye así sobre las mentes de quienes estén convencidos de que esta etiqueta corresponde imputarla justamente a ciertos tipos de conductas y situaciones, para apoyar la realización de esos tipos en especial, por encima o aun contra otras posibilidades de comportamientos sociales, y sea o no sea que aun estas últimas quepa invocarlas jurídicamente.

De ahí que, para quienes aspiran a obtener o conservar ciertas aspiraciones sociales, eventualmente controvertidas, conviene conseguir cobijarlas bajo la rúbrica DD.HH. En el imaginario social, la inclusión dentro de tal casillero lingüístico puede reforzar el poder de convicción para imponer aquellas en ese medio, incluso por vías legislativas o judiciales. En efecto, la categoría semántica DD.HH. acarrea, por su poderosa connotación de direccionamiento en sentido emotivo favorable, unos sensibles efectos pragmáticos de apoyo hacia lo catalogado así, entre quienes aceptan esa imputación para los objetos de referencia sociales incardinados bajo ella.

1 Estas tres citas corresponden respectivamente a: KOLAKOWSKI, 1975, p. 63; TOPITSCH, 1971, p. 95; VAZ FERREIRA, 1963, p 145. [Los énfasis mediante negritas se añaden aquí.] 
Es natural que tal aceptación dependa, al menos en cierta medida, de ideas que la gente se forma al respecto (acertadas o no), como pasa con toda doctrina política. Ahora bien, los académicos que se ocupan de estudiar la materia-DD.HH. suelen pensar que entre las ideas-fuerza que la conforman interviene, y por cierto con importancia decisiva (a juicio de aquellos), el papel desempeñado por unos "fundamentos", muy singulares, los cuales obrarían ahí desde la propia raíz sobre cómo esos derechos son concebidos y cómo se manejan de hecho.

No ha dejado de ser advertido, desde tiempo atrás (Topitsch, Bobbio, Mourgeon, también otros), lo artificiosas que suelen ser las teorizaciones sobre "derechos humanos". Entre ellas, justamente ocupa lugar muy destacado lo que se invoca a título de dichos “fundamentos". Años atrás di a conocer un ensayo (2004b) ${ }^{2}$ donde procuré explicar por qué esto último no tiene repercusiones si no es en discursividades académicocelestiales; y suele constituir un disfraz retórico cuando esto es traído a colación en el ámbito judicial o cuando se lo hace parte de discursos públicos de orden ceremonialinternacional. Subrayé ahí que las formulaciones de "fundamentos" invocadas son superfluas, tanto en la práctica como para guiar el conocimiento real sobre las actividades humanas sustantivas en los campos sociales correspondientes. No es siguiendo semejantes elucidaciones sobre "fundamentos" cómo son determinados realmente, ¡en la práctica!, los contenidos específicos de los comportamientos efectivos que cumplen los protagonistas mismos de estas actividades: operadores oficiales, ciudadanos en general. Dichas aproximaciones son infértiles para proporcionar información propiamente dicha -ni empírico-fáctica, ni con respecto a estructuras mentales decisivas - sobre cuanto pasa de veras al invocar estos “derechos”3.

En definitiva, las teorizaciones de ese género dan cuenta de aspectos que pertenecen respectivamente a uno u otro(s) entre tres grandes planos de cuestiones: [a] facticidades, [b] discursos normativos, [c] creencias metafísicas. Sin embargo, en tales teorizaciones no se suele tomar en cuenta diferencias de fondo que son de alcances claves para examinar tales respectos. Estas diferencias, cruciales, emanan de heterogeneidades básicas en cuanto a los aspectos siguientes.

\section{En dos planos estrictamente cognitivos:}

[a] El membrete "fundamentos" se hace apuntar a ciertos órdenes de fenómenos del comportamiento humano dados empíricamente o a unos previsibles, cuyo estudio

\footnotetext{
2 Advertencia. En esta y las demás referencias bibliográficas para las que ahí mismo queda indicado únicamente el año de esa publicación, sin nombre de autor, se trata de trabajos que me pertenecen (E.P.H.), consignados en las listas $a$ ) y $b$ ) de la Bibliografía ubicada al final del presente estudio; el año señalado, en esas referencias, es el de la publicación a que corresponde así tal remisión.

3 Sobre las posibilidades (¡sus inevitables límites!) de ofrecer fundamentaciones es insoslayable tener muy presente las cardinales puntualizaciones presentadas al respecto por ALBERT, 1973: esp. [especialmente] $\S \S 2$ (pp. 3 y ss.: "El principio de la fundamentación suficiente y el trilema de Münchhausen”) y 9 (pp. 84 y ss.: "El problema de la fundamentación de convicciones éticas”). Ofrezco precisiones complementarias en 2006, Sec. B.I (pp. 76 y ss.: "Fundamentaciones e intersubjetividad. Lo racional y lo razonable"); cf. esp. su § 2 (pp. 79 y ss.: "Fundamentos") [o véase las partes correspondientes en 2012a].
} 
específico es objeto de las ciencias sociales (Psicología, Sociología, Economía, Politología, Antropología u otras); en cambio, resulta confusionista entender referirse a tales investigaciones bajo dicho membrete.

[b] O bien, se procuraría señalar unas estructuras del pensamiento, sean de orden lógico-formal o psicológicas; mas he aquí que en ninguna de estas dos esferas esos presuntos "fundamentos" se revelan como necesarios o ni aun como habituales.

\section{En un plano METAFÍ́sICo:}

[c] Se hacen valer además ciertas creencias en tales o cuales "fundamentos" extraempíricos o supra-empíricos. Sean ellos cuales fueren; no son reconocibles mediante la razón laica: constituyen postulados de $f e$, no elucidables sino en órdenes de pensamiento teológicos o parateológicos.

Los tres planos suelen presentarse entremezclados bajo la etiqueta "fundamentos", cuando aparece aplicada para plantear las supuestas justificaciones de fondo sobre por qué hay lo que se denomina DD.HH. Todo ello en simbiosis, además, con precomprensiones esencialistas $^{4} \mathrm{y}$ en general constituyendo unos modelos mito-platonizantes ${ }^{5}$ de entender las dinámicas del pensamiento normativo.

Ahora bien, años antes de escribir yo aquel ensayo, el destacado profesor español Gregorio Robles había publicado unos breves trabajos que se concentran específicamente en cuestiones de "derechos humanos" (así las llama él mismo), textos que después reunió en un pequeño libro (1992). El primer estudio de esa compilación se titula, justamente: “Necesidad de fundamentar los derechos humanos" [cursiva mía, E.P.H.]. La tesis central defendida ahí es, o en todo caso parece ser, ni más ni menos que diametralmente contraria a la sustentada luego por mí. Al redactar mi texto inicial sobre ello (año 2000), y cuando lo revisé después (año 2003) para presentarlo en Doxa (publ. 2004b), no estaba yo enterado sobre la existencia de dichos ensayos. Algunos años más tarde, su autor tuvo la gentileza de obsequiarme dicha publicación, gracias a lo cual puedo considerar los puntos de vista que examinaré aquí.

4 Cf. ALBERT, 1987: § 13 (“Der Essentialismus und die Suche nach letzte Erklärungen” [El esencialismo y la búsqueda de explicaciones finales]). Por mi parte: 2006, Sec. C.5 (pp. 204 y ss.: "Esencialismo"); y muy ampliamente en 2012a, Tema 8 del t. III (pp. 475 y ss: "Esencialismo y ‘naturalezas jurídicas’ (Caminos en el ‘cielo’ para la doctrina del derecho)”); vid. también 2008, § VI (pp. 25 y ss.: "Esencialismo normativista y sus tributos al pensamiento mágico”).

5 Cf. ALBERT, 1972. Si bien ahí ese autor examina sobre todo tales formas de pensamiento en modos de teorización de los economistas, la crítica central al respecto es aplicable también, mutatis mutandis, al normativismo jurídico en general: "Die Nationalökonomie scheint einen Objektbereich zu behandeln, der sich ohne weiteres erfassen und erklären lässt, ohne daß man auf Ergebnisse der soziologischen und sozialpsychologischen Forschung zurückgreift” (La Economía Nacional pareciera ocuparse de un campo de objetos que simplemente sería dable captar y aclarar sin acudir a resultados de la investigación sociológica y socialpsicológica) [op. cit., pp. 417 in fine-418 in limine]. 
Considero que vale muy bien la pena detenerse en el planteamiento de Robles, no es común encontrarse con razones principales tan sugestivas — ¡de orden laico! en apoyo de esa supuesta necesidad; por lo demás, él las explica sin desviar la atención hacia pedantismos doctrinarios enredadores, en pocas páginas. Si algo puede alegarse con cierta plausibilidad intelectual a favor de dicha pre-suposición habitual, semejante "necesidad”, difícilmente se cuente con argumentos mucho más atendibles (por cierto lo son a primera vista) que los invocados por él allí. Estos conservan toda su relevancia, siempre y cuando se consienta la petición de principios de abocarse a escudriñar la existencia de "fundamentaciones" (en sentido estricto) para los DD.HH.

En atención a esta pertinencia académica que, sin duda, argumentos como los invocados por Robles siguen revistiendo, en el plano de las concepciones idealizantes sobre la materia-DD.HH., aquí voy a tratar de hacer ver por qué ellos son intrínsecamente engañadores. Obviamente, para reflexiones básicas sobre cuestiones de ideas sociales, máxime cuando estas últimas vienen de muy atrás y siguen siendo manejadas en el presente, su valía e interés no depende de la fecha en que esas consideraciones hayan sido dadas a conocer, sino de su agudeza en sí.

Dejo señalado de antemano en dónde afinca la “tramposidad” de los planteamientos que examinaré: gran in-determinación en el uso del término "fundamentar" + recurso a unas generalizaciones in-discriminadas + falacia intelectualista-wishful thinking (visión “misionera”). En síntesis: abundancia de fórmulas vacías/extraempiricidad.

De hecho, esas fórmulas vacías sirven para apartar la vista de dónde reside el quid verdadero — controversias de ideologías, conflictos de intereses y demás - en los asuntos para los cuales son invocadas. Aquellas representan, por lo general, unos acuerdos de palabras, facilitando así el prescindir de poner sobre el tapete los desacuerdos que en la realidad hay sobre la práctica; o bien, si estos últimos salen a relucir, aquellas fórmulas permiten cubrir retóricamente mediante un manto de aparente universalidad la solución encomiada en el alegato respectivo.

Nota: Fórmulas vacías. - Una fórmula lingüística tiene contenido propiamente normativoregulativo si de veras su esfera de aplicación excluye - $-\mathrm{y}$ esto en forma netamente intersubjetiva - ciertas conductas, actitudes, formas de pensar u otros datos, circunscritos de manera suficientemente precisa. A menudo no es así para todo o parte de lo que dice un precepto moral o una norma jurídica. Ahí tenemos que vérnoslas con lo que técnicamente se denomina: las fórmulas pseudo-normativas, aquellas cuyo mandato se presta a múltiples suertes de interpretaciones divergentes para decidir las acciones efectivas. Tales fórmulaciones constituyen el tipo más extremo de conceptos indeterminados. Si bien aun ellas no son completamente “vacías”, pues así y todo permiten excluir algunas posiciones muy extremas, empero para las posiciones que al respecto son objeto de serias discusiones en la práctica, justamente estas son las que tales expresiones NO logran excluir (si bien los partidarios de todas las posiciones en juego aseguran que son solo ellos mismos, respectivamente, quienes responden al “verdadero” sentido de la fórmula invocada) 6 .

6 Cf.: DEGENKOLBE, 1965; TOPITSCH, 1972, § 6 (pp. 26 y ss.); KOCH, 1977, § I.2.b (pp. 23 y ss.: "Das Grundgesetz: Eine Sammlung von Leehrformeln?” [La Constitución: ¿Una colección de fórmulas vacías?]). - Complementariamente, en mi 2006: Sec. C.I.4 (197 y ss.: «Fórmulas vacías pseudonormativas») [o 2012a: Sec. D.II.3]. Unos cuantos ejemplos de fórmulas vacías típicas se recogen en 2016a: \# 262 y 332. 


\title{
II. PLANTEAMIENTO GENERAL DE LA TESIS ACADEMICISTA: SUPUESTA “NECESIDAD” DE “FUNDAMENTAR” LOS DD.HH.
}

Robles toma como punto de partida la célebre sentencia de Bobbio, con la cual ciertamente estoy muy de acuerdo: "Hoy el problema de fondo relativo a los derechos humanos es no tanto lo de justificarlos, sino cómo protegerlos. No es un problema filosófico, sino político"?

Ahora bien, lo interesante es que Robles sustenta ni más ni menos que la tesis opuesta a dicha afirmación:

\begin{abstract}
"Porque un problema sea de difícil solución no tenemos derecho a abandonarlo o a calificarlo de pseudoproblema. Un problema lo es cuando se nos plantea la interrogante respecto de algo, y carece de sentido negarlo porque no conozcamos la respuesta, o porque creamos que desde nuestros planteamientos intelectuales no es posible hallarle cabida" $(11 \text { y s. })^{8}$.
\end{abstract}

No dejo de reconocer que tal aseveración es atinada como un principio general de orden heurístico. Pero la pregunta decisiva es, no menos para nuestra cuestión que para cualquier otra: por cuanto se refiere específicamente al asunto propio en examen, ¿no será que este "problema” particular, el planteado así, constituye un falso “problema”? ¿No es posible que la verdadera solución, para eso que Robles ve ni más ni menos que como todo un "problema", sea lograr advertir, por el contrario, que la clave ahí es saber dirigirse antes bien a: "Mostrarle a la mosca la salida de la botella ['fundamentos'] cazamoscas”? (Wittgenstein) ${ }^{9}$.

En efecto, no cabe dar por descontado sin más, simplemente a priori, que estemos de veras frente a una pregunta eventualmente solucionable (al menos en parte); que entonces sólo se trate, en efecto, de que es "difícil” alcanzar a divisar su respuesta verdadera, por más que sin duda (¿en apariencia?) la haya realmente. Esto último no se ve por qué deba ser admitido porque sí; a no ser bajo la pre-suposición de que, ipor fuerza!, cualquier interrogante dirigiere necesariamente la atención hacia determinada contestación sensata congruente con los propios términos en que fuere formulado él mismo, sea este cuál fuere. Pero prefiero pensar que la argumentación de Robles sobre este asunto no entiende basarse en última instancia sobre ni más ni menos que tal petición de principios (irrebatible por definición), tomarla como regla simplemente absoluta, sin más. Por eso pienso que corresponde examinar una por una las fundamentaciones específicas invocadas por él.

Sobre cómo funcionan los conceptos indeterminados en los discursos-DD.HH. en general, vid. 1986e: § 20 (275 y ss., “Tres clases de conceptos jurídicos indeterminados con referencia a los derechos humanos”).

7 BOBBIO, 1982: 128 (trad. corregida aquí). Sobre esa cuestión principal, la realizabilidad política, véase el imprescindible librito de MOURGEON, 1978.

8 Advertencia: citas de ROBLES, 1992. En las transcripciones que efectúo de este autor indico nada más (por lo general es entre paréntesis) que la numeración de las respectivas páginas de dicha obra; los énfasis mediante cursivas o VERSALITAS son añadidos por mi propia cuenta (E.P.H.) — salvo si queda señalada la advertencia: curs. del A.- .

${ }^{9}$ Investigaciones filosóficas: $§ 309$. Y antes Vaz Ferreira: véase su cita correspondiente a la n. 1, supra. 
Veamos, pues, si las puntualizaciones de nuestro autor logran acreditar que el asunto-DD.HH. — no cualesquiera otras cuestiones, entre las habidas y por haber — se sustenta en alguna "necesidad” verdadera de "fundamentar", y cuál sería esta misma. Él procura demostrar que tal "necesidad” existe en efecto, sería ni más ni menos que menos que justamente así:

“... por varias razones. La primera, porque es absurdo defender unos valores y no saber por qué. La segunda, porque dicho porqué o fundamento delimita el contenido concreto, en una u otra dirección, de los derechos humanos. La tercera, porque resulta francamente ridículo e inaceptable que nosotros, los teóricos, presentemos teorías sobre los derechos sin [curs. del A.] FUNDAMENTARLAS. Y, por último, la cuarta, porque para llevar a la práctica dichos derechos es preciso, por lo menos, tener las ideas claras. A la primera la llamaremos la razón ética, a la segunda la razón lógica, a la tercera la razón teorética y a la cuarta la razón pragmática” (12).

Analizaré cada uno de estos cuatro tipos de “razones”. Eso pondrá de manifiesto que ellas consisten en unas ideas cuyas cardinales faltas de precisión, sus vastísimos niveles de vaguedad, inhiben aquilatar de QUÉ pueda ahí tratarse realmente ${ }^{10}$.

\section{III. “RAZÓN” PRIMERA: ¿ES UNA CUESTIÓN DE MORAL?}

Escribe Robles: "La razón de tipo moral salta a la vista: no podemos defender ni realizar los derechos humanos si no estamos convencidos de su BONDAD moral... Fundamentarlos significa

${ }^{10}$ Precisión y conceptos indeterminados, "celadas" lingüísticas. - "Un concepto ' $\mathrm{t}$ ' es preciso = df.: todas las personas que entienden ese lenguaje (técnico, profesional: Fachsprache) en el cual este concepto se halla definido, o que conocen las reglas semánticas del concepto, se hallan en condiciones de decidir, ante cualquier evento completo [esto es, se conocen todos sus datos relevantes al respecto], si ese evento corresponde o no a los objetos designados por ' $\mathrm{t}$ ' ” (OPP, 1970: 139, curs. E.P.H.). Por lo demás, vid. VAZ FERREIRA, 1963, cap. "La falsa precisión”; y téngase presente en general la conocida advertencia general wittgensteiniana sobre los "encantamientos" del lenguaje. Por lo demás, también ahí juegan papel protagónico las características principales de engañosidad que conllevan los usos del lenguaje habituales en las ideologías colectivas [cf.: BERRGER y LUCKMANN, 1968; TOPITSCH, 1971 y 1988; WELDON, 1953; MELLIZO, 1968], a cuya impronta por cierto no es ajeno más de un grupo de discursos de las ciencias sociales (como desde luego, entre ellos, el pensamiento jurídico profesional). — Más de una vez llamaré la atención sobre las decisivas carencias de precisión que afectan a las categorías conceptuales básicas manejadas por Robles. En cuanto a las condiciones y alcances de los requerimientos de precisión en general, señaladamente para discursos de las ciencias sociales, puede verse 2012a: Secs. B.I.4 (pp. 103 y ss.: “Carácter no 'exacto’ del lenguaje”) y B.I.7.b (pp. 114 y s.: “Vaguedad y precisión”), C.I.5 (pp. 209 y ss.: “ ‘Claridad’ y precisión”), D.I.3 (pp. 365 y ss: “¿Cómo son ‘claras’ las disposiciones jurídicas?”) y D.I.7 (pp. 420 y ss: “Conclusiones generales sobre la factibilidad (grados y límites) de otorgar precisión al lenguaje jurídico”), D.II.2 (pp. 430 y ss.: “Conceptos jurídicos indeterminados”) y D.II.3 (pp. 440 y ss.: "Fórmulas vacías pseudonormativas") [estos dos últimos ítems, los señalados para la Sec. D.II, se encuentran ya en 2006: respectivamente, Sec. C.I.3 (pp. 192 y ss) y C.I.4 (pp. 197 y ss.)]. Mi examen más amplio sobre "La presencia de los conceptos indeterminados en el discurso de los derechos humanos” se encuentra en 1986e: cap. III (pp. 241 y ss.); más breves, 1984a y 1984c (Sec. I). Sobre las características principales de engañosidad que afectan a los usos del lenguaje en las ideologías colectivas, inclusive a más de un discurso de las ciencias sociales (y notablemente, entre ellas, al pensamiento jurídico profesional), puede verse el panorama general básico al respecto en 2012a: Sec. B.I (pp. 83 y ss.: "Nociones básicas sobre la naturaleza del lenguaje”) y B.II (pp. 120 y ss.: "Celadas lingüísticas”) [o bien, sin unos desarrollos adicionales incorporados en 2012a, la versión previa ofrecida en 2010a: Sec. D.I-II (\# 104-123)]. 
llegar a esta convicción. Si nos falta ésta será inútil todo lo demás... [De ahí,] la importancia de ésta (razón moral) precisamente también para la puesta en práctica de dichos derechos” (12).

No niego que las “convicciones” de los protagonistas, ahí como para toda conducta humana volitivo-consciente (sean cuales fueren los factores que producen los respectivos estados mentales en cada quien), suelen desempeñar un papel codecisivo para impulsar o para frenar los comportamientos en cuestión. Mas nuestra pregunta es otra: no si tales "convicciones” existen y a menudo tengan ciertas eficacias (unas veces sí, otras no), sino saber qué es "necesario" de veras — ¿o no?_ para que tales pensamientos estén ahí, llámesele o no "fundamentos" a todo o partes de este "qué".

Como he subrayado al principio, el término "fundamento" lo hallamos empleado de una u otra entre tres grandes maneras para comprenderlo, referidas respectivamente a: 1) facticidades (unas de naturaleza psicológica o unas "externas", y ya sean individuales o grupales), 2) "gramáticas” discursivas, 3) entes metafísicos. Ahora bien, ¿de acuerdo con cuál de tales maneras, o serían a la vez dos o las tres, o acaso según alguna otra, emplea Robles dicho término?

En el pasaje transcrito, al parecer se llama "fundamentarlos" al proceso mental por el cual se "llega" a una "convicción". Entonces bastaría, para entender que estamos ante "fundamentación" propiamente, con que al resultado final indicado se arribe ("llegar") mediante alguna manera de pensar, sea esta cual fuere. Vale decir: "fundamento" sería, ahí, cualquier vía de pensamiento que en los sujetos los haya impulsado a estar convencidos de la "bondad moral" considerada. Si es eso lo que Robles quiso decir, desde luego es verdad tal afirmación, no menos indiscutible que trivial: ¿quién va a negar que a la susodicha "convicción”, como a cualquier otra, se "llega" mentalmente de alguna manera? Desde luego, se piensa que los DD.HH. son cosa "buena"... pero: ¿hacen falta, de veras, unos especiales procesos mentales llamados "fundamentación”, para obtener — ¡únicamente si es así! — que cada quien logre convencerse de esta bondad?

La pregunta relevante, para acreditar esa aseveración de Robles, es: ¿cómo se "Ilega”, en qué consiste este "llegar", cuáles son sus componentes mentales propios? ¿Para esos efectos serviría cualquier "fundamentación”? Supongo que él no habrá querido decir esto último. Solo que, a falta de aclaraciones sobre ello (no veo que sean obvias o sencillamente triviales), los alcances reales de su respuesta quedan en pleno misterio. Salvo que esté dando por sobreentendido que las "fundamentaciones" a que se refiere son simplemente unas que es fácil hallar en la literatura de esa materia. ¿Quiere decir, entonces, que aceptables serían todas estas mismas, aunque discrepen parcialmente entre sí? ¿ $\mathrm{O}$ es que, al fin de cuentas, se trata de las que cada quien elija $a$ piacere entre aquellas? ¿O bien, en cambio, aceptables no serían sino alguna(s) en particular entre todas las "fundamentaciones" invocadas?; pero, ¿cómo saber en cuáles de ellas creer, por qué sí o por qué no?

Por lo demás, aunque uno esté convencido de saber bien qué "fundamentaciones" serían las acertadas, siendo además cierto que tales precisiones le importen mucho a uno mismo y a unos cuantos estudiosos de la materia: ¿basta con tal 
convicción, académica, para demostrar que el mismo orden de convicciones anide como causa eficiente, al menos inconscientemente, en las propias cabezas de los protagonistas comunes (activos o pasivos) de las conductas-DD.HH.? ¿Qué pruebas empírico-sociales se conocen de que a todas o casi todas, o al menos gran número entre, las personas en general que “creen” en esos mismos “derechos” les importe también — ¡a ellas mismas! - estar al tanto igualmente de esas filigranas discursivas, por más interés que estas recojan en ciertos círculos profesorales?

\title{
IV. “RAZÓN” SEGUNDA: ¿ES UNA CUESTIÓN DE LÓGICA?
}

\begin{abstract}
Escribe Robles: “La razón de tipo lógico, o de coherencia... el fundamento DELIMITA materialmente [curs. del A.] el contenido de éstos (derechos), puesto que los penetra... la regulación real de la vida humana exige concretar contenidos, exige bajar de la retórica vacía de lo biensonante a la especificación y concreción de los ideales y valores... el acuerdo en el porqué es previo, condición necesaria del acuerdo en el qué”. [Y se cita en la n. 2: “... estamos de acuerdo tocante a esos derechos, pero con la condición de que no se nos pregunte el porqué (curs. en el original). En el porqué es donde empieza la disputa”.] (13).
\end{abstract}

Aun haciendo abstracción de lo medular que ahí es la falacia intelectualista (Wallas) en que se asientan estas afirmaciones, y desde luego admitiendo como sobreentendido que el autor no entiende referirse ahí a una "coherencia" en términos meramente de unos catálogos en artificios algebraicos llamados lógica "deóntica" salta a la vista que también aquellas pertenecen al reino de las vaguedades de vaguedades; y sobre todo, carecen de comprobación empírica. ¡Dios sepa CóMO se realice, en la práctica, ese supuesto “delimitar” (¿intersubjetivamente?), “concretar [¿intersubjetivamente?] contenidos”, elegir en qué fijarse para calibrar si se den o no se den ahí unos tipos de "coherencias" (y entonces considerando, a su vez, como faltos de “coherencia” otros modos de pensar corrientes)...!

Tales “cómo" no son nada obvios, máxime habida cuenta de las netas discrepancias al respecto entre operadores efectivos de los discursos reales correspondientes. Eso sí, me refiero a las discrepancias irrumpidas una vez que el asunto es "bajar" desde las afirmaciones general-generalísimas de principios "biensonantes” (p. ej., Declaración Universal de Derechos Humanos), indisputables en planos de la law in books, y en cambio desempeñar las law in action del mundo terrenal $^{12}$. Muy al contrario de eso que postula la cita contenida al final de la trascripción efectuada, las discrepancias decisivas reales se dan con respecto a la realización del "qué", sea lo que fuere cuanto se quiera pegarle como adorno en cuanto al "porqué" (i.e., unos llamados "fundamentos"). No es sino cuando a título de "qué" se considera simplemente la letra de ciertas disposiciones oficiales, o si la atención queda restringida a fijarse sobre todo en unas vaguedades doctrinarias concomitantes, entonces resulta que es esto mismo (letra) lo que no suele ser puesto en duda como tal: ¡law in books!

11 Cf.. 1996a (y sobre todo véase la literatura crítica indicada ahí).

12 Vid. LLEWELLYN, 1930 [resumen en mi 2012a: Sec. D.III.6 (pp. 481 y ss.: “Paper rules”)]. 
Sea como fuere, las "delimitaciones" reales no son el resultado de ninguna suerte de "coherencia” en abstracto. En realidad dependen, antes que nada, de los hábitos mentales dogmáticamente introyectados en la socialización —la general y la académica- de sus protagonistas. Y también depende de las circunstancias sociales efectivas — ichica cosa! - que permitan o no permitan, a esos protagonistas, proceder de acuerdo con sus preferencias en la materia [cf. 2015b]. La suposición de que "el acuerdo en el porqué es previo, condición NECESARIA del acuerdo en el qué", no está sustentada en comprobaciones sobre cómo funciona ello en el mundo social empírico. Tal suposición constituye una fantasía intelectualista, su vigencia no alcanza más allá de ciertos rubros de pensamientos que circulan en algunos sectores del mundo profesoral.

Nota: La falacia intelectualista. - “... what may conveniently be described as the Rationalist Fallacy in political thinking: namely the assumption that human beings largely act in politics [y en general en sus conductas sociales] upon rational motives and trains of intelligent reasoning. We in our time, alas, know what fatuous nonsense this is"; se trata de "the 'intellectualistic' assumption, that every human action is the result of an intellectual process, by which a man first thinks of some end which he desires, and then calculates the means by which that end can be attained” (Wallas, 1962: 1 y s., 5; con curs. añadidas aquí). [Sobre unas puntualizaciones básicas (¡imprescindibles!) que trae ese viejo libro, relativamente breve pero inusitadamente iluminador acerca de la materia empírica de las ciencias sociales, es llamada la atención también en mi 2012a: Sec. C.6.k (“La falacia intelectualista”).]

De tal ilusionismo intelectualista básico, en amalgama con una pléyade de idealizaciones de variopinta suerte, emanan los tipos de aproximaciones (¡normativismo jurídico!) que conforman la "Santa Familia” moderna acreditada en conocidos estudios que responden a unas modas académicas hegemónicas en la materia, con respecto a los discursos de derecho, ética, política: Rawls, Habermas, Alchourrón y Bulygin, Dworkin, Alexy, Ferrajoli, Nino, Ost, Atienza y muchos más [cf. esp. 1996b, 1997, 1998, 2007 y 2009; a ello se refieren también 2013b, 2015a, 2018c y 2018e; vid. además Salas, 2013 y 2017]. Si bien se mira, tales modelos de discursos idealistas consisten básicamente en hacer abstreacción del hecho más decisivo para las prácticas efectiivas en las materias respectivas, esto es: “... que existe un trasfondo esencialmente sociológico, socio-histórico y cultural, que para nosotros habría de constituir el tema de lo que cabría llamar un análisis de formas de vida, si es que se permite adoptar la expresión de Wittgenstein 'Lebensformanalyse'. Todo lo relacionado con ello habría de ser para nosotros más fundamental que el análisis del discurso mismo" (Toulmin) [Atienza y Jiménez Redondo, 1993: 331, curs. E.P.H.].

Para precaverse de dichos ilusionismos, u otras teorizaciones despistadoras que gozan de señalado renombre actualmente en cátedras universitarias [así, las “imposturas intelectuales” que se cobijan bajo la etiqueta postmodernismo (cf. Sokal y Bricmont, 1999) o confusionismos mixtos como los pregonados por Rorty], es indispensable atisbar mucho más allá de cuanto atienden las elucidaciones iusnormativistas [cf. 2013b]. Esto es: no apartar la vista — tanto da si se hace por desconocimiento o por comodidad (más vale no meneallo...) - de lo sacado a luz en cruciales exámenes, muy minoritarios y desde luego pasados habiutalmente en silencio, que no comulgan con tales modas. Por cierto, estos otros distan bastante de lo “académicamente correcto" para esas materias en nuestros días [así los planteamientos, singularmente realistas, con que esas cuestiones se abordan por medio de estudios como los indicados en la lista (c) de la Bibliografía que se consigna al final del presente estudio; y vid. 2018c, 2018f, 2019b]. 


\section{V. “RAZÓN” TERCERA: ARGUMENTO TEÓRICO}

Escribe Robles: "El argumento de tipo teórico nos afecta a nosotros directamente, a los teóricos del derecho y de la sociedad (...) ¿Qué clase de teóricos seremos si nuestras teorías las presentamos sin fundamento? (...) ¿Con qué derecho podemos exigir que se crea en la bondad de lo que defendemos si no somos capaces de fundamentarlo? (...) Y sobre todo: NO PUEDO SABER cuáles son éstos (derechos) y cuál es su contenido concreto si eludo el problema del fundamento, ya que éste constituye la úNICA vía de concreción. No hay realización sin fundamentación, como no hay práctica eficaz sin ideas elaboradas y colectivamente asumidas” (14).

Estas afirmaciones contienen por lo menos las siguientes "celadas" de razonamiento, decisivas:

a) Atento a la enorme indeterminación con que ahí se emplea la familia de palabras "fundamento", "fundamentarlo" y "fundamentación”, resulta imposible someter al examen de eventuales falsaciones empíricas esas tajantes afirmaciones sustentadas de tal manera: “...no puedo saber...”, “... la única vía...”, “No hay realización...”, y demás. Por supuesto que en algún sentido (¡sepa cada quién cuál!) habrá "cosas" que, hasta si un teórico se refiere a ellas de tales modos, aun diciéndolas así pueden aludir a aspectos que no son imaginarios con respecto a esos derechos. Pero si no se empieza por precisar cuáles serían específicamente estas “cosas", las identificables concretamente bajo el rótulo "fundamentos", entonces resulta imposible averiguar cómo pueda juzgarse si ello es verdad o no, para cada una de ellas. Suponiendo que tales "cosas" no sean simplemente las mismas ya aludidas en los dos puntos anteriores, paso a distinguir en especial dos afirmaciones de las líneas recién transcritas.

b) Al parecer, también Robles incurre en la candidez profesoral típica de suponer que nosotros, los “teóricos”, estemos en condiciones de “exigir” a otras gentes que estas "crean" en aquello que "defendemos". En todo caso, acontecería justamente esto: ¡...en tanto en cuanto "somos capaces de fundamentarlo"! Sin embargo, aun bajo la suposición de que lo así señalado tenga buena aceptación profesoral, no es de ver por qué, y muchísimo menos aún cómo, ello vaya a repercutir necesaria o probablemente — iy entonces hasta decisivamente! — sobre las prácticas de los protagonistas habituales de esas esferas de conductas. Este "necesariamente", o digamos "probablemente", implica dar por sentado que a nosotros, los académicos que andamos desvelándonos por acertar sobre asunto como ese de los "fundamentos", nos es dable lograr la hazaña siguiente. Ni más ni menos que el colocarnos en situación de poder "exigir" (en todo caso sería en algún sentido débil de esta palabra, digamos: "plantear” o "sugerir"), en general con buenas probabilidades reales de ser escuchados por los protagonistas efectivos de las conductas en cuestión, que una buena porción de estos mismos vengan a reconocer de veras la "bondad" (entendido también que esto quiere decir: la verdad, no principalmente un mero juicio de valor) de nuestras tan bienintencionadas recomendaciones. Y que, inclusive, entonces esos protagonistas hasta se preocuparán por HACERLE CASO a dichas recomendaciones en sí mismas... ¡ wishful thinking! ${ }^{13}$.

13 Véase también 2012a: Sec. C.II.6 (pp. 147 y ss: “Magia verbal (verbalismo) y ‘wishful thinking’ ”). 
Esas perspectivas de "exigir" son, específicamente: una simbiosis de falacia intelectualista con visón "misionera” acerca de las ciencias sociales. Esto último ${ }^{14}$ es propio de la ideología gremial que es común a los científicos sociales en general. En efecto, ellos suelen concebirse a modo de una suerte de médicos para programar las ordenaciones de lo social (ecos de la función que asumen los sabios en la República de Platón o en las ilusiones de Comte, iy ni qué hablar de las mistificadoras categorías de examen propios de las sociologías marxistas!). Se autoperciben en calidad de llamados a cumplir el papel de suministrar las recetas capaces de curar deficiencias sustanciales en las conductas colectivas; es así cómo esas profesiones se legitiman ante el imaginario social.

c) Supuestamente: abordar "el problema del fundamento... constituye la única vía de concreción [de tales derechos]. No hay realización sin fundamentación, como no hay práctica eficaz sin ideas elaboradas y colectivamente asumidas". - Afirmar tal "no", y más que más lo de "única vía”, hace a un lado las experiencias sociales ampliamente dominantes (a menos que, una vez más, el término "fundamento” pueda significar ahí casi cualquier “cosa”). Las mentes reales de los protagonistas reales comunes de los comportamientos-DD.HH. reales, ESTAS mentes no se ponen a hurgar en la literatura sobre "fundamentos" para decidirse a actuar de unas u otras maneras; y menos que menos, por supuesto, se preocupan de efectuar tales disquisiciones ellos mismos. Ni aun los operadores jurídicos profesionales suelen hacer depender, ¡de veras!, de semejantes indagaciones lo que resuelven en la práctica. ¿Se conoce alguna investigación empírica de campo, vale decir, no simplemente el crédito otorgado a unas afirmaciones apriorísticas procreadas por la falacia intelectualista, donde se comprueba lo contrario?

d) Otra gran generalidad-generalísima: “... no hay práctica eficaz sin ideas elaboradas y colectivamente asumidas”. Bueno, sí... pero ¿qué quiere ahí decir “colectivamente”? Desde luego, para que tengan lugar unas prácticas sociales, estas necesitan ser conocidas y aceptadas por buen número de individuos. Mas la cuestión es, con respecto a cada una de ellas: ¿cuáles sectores de individuos, o qué partes sí y cuáles no de alguno(s) de estos grupos sociales, las “asumen” efectivamente, y en qué consisten realmente tales prácticas (con qué grados de uniformidad o de variedad, etc.)? Nada de eso es dable saberlo, ver si es cierto o no, con sólo decir que por ahí andan unos "fundamentos" que acaso (ipruebas empíricas no hacen falta!) aniden en las cabezas de muchos o pocos de esos sujetos.

${ }^{14}$ Vid. 1997 (breve) o 2010b (amplio). 


\section{VI. “RAZÓN” CUARTA: ARGUMENTO PRAGMÁTICO}

Señala Robles: “... argumento pragmático... Carece de sentido luchar por algo sin saber por qué se lucha” (15).

Este "por qué" consistiría, pues, ni más ni menos que en los fundamentos considerados. La cuestión es, una vez más, saber a qué suertes de "por qué" entienda referirse Robles. La respuesta suya es simplemente que, aun para este cuarto "argumento”, su contenido resulta y se justifica así: “... de lo dicho [previamente sobre los 'argumentos' anteriores] se desprende claramente” (15) incluso este último, el cuarto. Por ende, agrego yo, también en cuanto a este corresponden al menos los decisivos reparos que he ido señalando acerca de los otros tres "argumentos”.

De todos modos, sean cuales fueren los "por qué" en cuestión, no hay motivo para dar por pre-supuesto que ahí sean "necesariamente" lo mismo (o poco más o menos) los dos planos siguientes. Plano a): Lo propuesto en tal calidad por ciertas presentaciones de law in books, máxime unas "exquisiteces" doctrinarias ${ }^{15}$ como las elucidadas en la disciplina especial Teoría del Derecho. Plano b): Los "por qué” reales; o sea, cuanto resulte lo decisivamente motivante — ien la práctica! — en las maneras como lo de (a) obre — si es que de veras lo haga hasta cierto punto- sobre las mentes mismas de los actores jurídicos, en todos estos o al menos buena parte de ellos. Qué importancia efectiva puedan tener los "por qué" del plano (a) en las propias "cabezas" (b), semejante intervención está muy lejos de ser cosa obvia (a no ser en unos cultos a la falacia intelectualista). No es dable saber a qué atenerse al respecto si se prescinde de dejar netamente fijado, ¡antes que nada!, el objeto específico de investigación. Más esto último exige precisar dos órdenes de asuntos, a saber:

Por un lado, ¿CUÁLES serían específicamente en contenidos intersubjetivamente delimitados_ los “fundamentos" (plano a) en cuestión seleccionados para cada caso o tipo de casos? Puede que resulte no ser igual el grado de efectividad (plano $b$ ) — si acaso lo tienen— de ciertos postulados "fundamentales" (plano a) que el de otros postulados "fundamentales" (también plano a), para unas u otras especies de situaciones. ¡Diferencias decisivas!

Por otro lado, es indispensable delimitar muy bien, para saber de quiénes estamos hablando ahí, CUÁLEs serían los sectores de población (plano b) tomados en cuenta, o cuáles los grupos típicos de sentencias judiciales por examinar para comprobar si en realidad fue determinante ahí la consideración de esos mismos "fundamentos". Esto es: examinar si tal consideración, en caso de haber sido efectivamente manejada por jueces, haya sido de veras decisiva en dichas sentencias; 0 si acaso se trató más bien entonces de un complemento retórico, sin el cual el resultado jurídico hubiera podido ser prácticamente el mismo.

15 Cf. 2015a. 
Del modo, meramente abstracto-idealista (plano $a$ ), en que Robles encara el asunto de los "por qué", ninguno de esos dos extremos se alcanza a divisar, ni aun para obtener algún indicio sobre cómo se podría tal vez proceder a tratar de averiguarlo.

\section{VII. ...PERO, ¿QUÉ SIGNIFICA AHÍ “FUNDAMENTAR”? (falacias básicas)}

He insistido en señalar que Robles no aclara a qué llama "fundamentar" los DD.HH. Sin embargo, en otro ensayo suyo del mismo sitio, "El fundamento moral y el fundamento político" (29-32), él presenta unas anotaciones que al parecer permitirían reconocer cuáles puedan ser tales “fundamentos”. Allí nos dice:

"Si un determinado colectivo humano mantiene una determinada exigencia con el carácter de ‘derecho humano’ no puede limitar su argumentación a presentar políticamente tal exigencia, sino que tendrá que argumentarla moralmente, esto es conectarla con todo un sistema axiológico donde aquella se inserta. (...) Para el enfoque ético, la piedra angular es la convicción de la conciencia personal, mientras que para el enfoque político la clave es la convicción generalizada en el grupo, que no puede llevarse a efecto sino mediante el consenso” (30 y 32).

Me llevaría su buena extensión tratar de "higienizar” analíticamente, uno por uno (i.e., procurar diferenciar entre tipos característicos de sus respectivos múltiples contenidos semánticos posibles), los vastísimos ámbitos de vaguedad —con sus preconcepciones idealistas - que juegan "fuera de cámaras" bajo el velo de esos términos in-discriminantes, sobre todo los destacados especialmente por mí (mediante cursivas) en esta trascripción. Habría que detenerse a des-velar cómo tales recursos verbales conllevan, entre otras cosas:

- Falacias del Todo [Savater, 1989] o postulación de una unitariedad de los supuestos "intereses colectivos" [Ross, 1963: § LXXXIV]. Vale decir, ontologización de la etiqueta lingüística "sociedad", como si se correspondiese con la existencia de un Ser propio: de modo tal que Ello —i.e., i(cripto) unitariamente! ${ }^{16}$ — "mantiene una determinada exigencia..." ${ }^{\prime 17}$.

- Cardinales indistinciones entre "debe” y "es”, entre discursividad semántica y pragmáticas discursivas ${ }^{18}$. ¿Qué quiere decir aquí "puede” y "tendrá”?, ¿ ¿son lo mismo unos "consensos” terminológicos que "consenso" sobre la pragmática de esas mismas fórmulas?

\footnotetext{
16 Véase 2016a: Sec. C.II (74 y ss.: “Utilidad social (bienestar general, justicia social) y 'bien común’ (interés general)").

17 Véase: ARNOLD, 1962; BERGER y LUCKMANN, 1968; KOLAKOWSKI, 1975; OGDEN y RICHARDS, 1954; TOPITSCH, 1988.

${ }^{18}$ Cf. 2012a: Sec. B.I.3 (esp. 99 y ss.).
} 
— Unos mitos intelectualistas de "sistema"19.

- Indeterminación en cuanto a cuales sean los posibles modos —an heterogéneos y a menudo contradictorios, frecuentemente opcionales — de cuanto ahí se llama “conectarla"/’inserta". Hay modos muy variados de razonamientos jurídicos, y no pocas veces con consecuencias prácticas contradictorias entre sí, invocados para afirmar que se habría logrado justamente eso, para casos discutidos ${ }^{20}$.

- Etcétera... ${ }^{21}$.

Por cierto, no entiendo decir que tales disimulaciones discursivas y en general las básicas in-diferenciaciones que conducen a ello sean el propósito del autor ahí. Pienso más bien que no las ha advertido. Es lo habitual para las elucidaciones que sobre la materia presentan las law in books; también aparte de los estudios sobre derecho, pasa del modo más general en el pensamiento académico tributario de la falacia intelectualista en las ciencias sociales. - Sin embargo, hay una anotación realista efectuada por el propio Robles: “... es difícil encontrar sociedades plenamente homogéneas en sus concepciones morales [como tampoco en las interpretaciones de sus concepciones políticas]. La regla general es la heterogeneidad” (30). Esto es verdad; pero he aquí que planteamientos teoréticos como los de él están muy lejos de reconocer las consecuencias reales de tal comprobación, antes bien aparecen diluidas mediante sus idealizaciones discursivas generales.

19 Sistemas. — Toda suerte de creaturas mentales de tal índole (“esprit de géométrie”, dijo Pascal) dominan ampliamente en las ciencias sociales: unas falsas analogías frente al uso de ese mismo término, "sistema", en las ciencias de la naturaleza y en las meramente lógico-formales. A los especialistas en ciencias sociales les suele pasar desapercibido aquello sobre lo cual supo llamar la atención VAZ FERREIRA, hace más de un siglo: cf. "Pensar por sistemas y pensar por ideas para tener en cuenta" (1963: 154 y ss.). Por cierto, también LLEWELLYN tomó la precaución de advertir que: "Mientras para la 'sistemática' de las ciencias sociales las cosas marchen así, mejor renuncio a la palabra 'sistema' ” (1977: 20, trad. efectuada aquí). — A ello me he referido en varios sitios: 2000, parte II (pp. 574 y ss.: “Un modelo heurístico antifabulador y nada sistémico. Algunas 'ideas para tener en cuenta' ”); 2006, Sec. C.II.1 (pp. 231 y ss.: “La ilusión de venir a detectar unos 'sistemas” ”); 2010b, cap. II, § 4 (pp. 76 y ss.: “Ilusión, en las ciencias sociales, de proceder a detectar unos 'sistemas' (carácter sustancialmente heterogéneo y antinómico del comportamiento colectivo)” y § 7 (pp. 103 y ss.: “El mito de 'sistema’ en el pensamiento jurídico”) + Suplementos c (pp. 111 y s.: "Engañosidad de las formulaciones 'sistémicas' ”) y d (p. 112: "Modelos cibernéticos”); 2012a, Sec. E.I.1 (pp. 547 y ss.: "La ilusión de venir a detectar unos 'sistemas' (conformación muy heterogénea, contradictoria y variable de las conductas humanas y de los discursos correspondientes)”); 2015a, cap. III.4 (pp. 171 y ss.: “El mito de que el derecho positivo es un 'sistema' ”); el tratamiento más breve es el de 2000, mi desarrollo más amplio es lo presentado al respecto en 2010b. [Por cuanto dice referencia particularmente a Luhmann, vid. 2013b (p. 519 y ss.: "Un ejemplo: La vertebral falta de referentes empíricos netos — bien diferenciables como tales — en los desarrollos del tipo 'sistémico'-luhmanniano”).]

20 Vid. 2012a: esp. Sec. D (345 y ss.: “La 'lógica’ del discurso jurídico profesional”).

21 Tómese también muy en cuenta, de modo general, las “Celadas lingüísticas” señaladas en 2012a: Sec. B.II (120 y ss.) [o véase 2010a: Sec. D.II: \# 110-123 (132 y ss.: ““Encantamientos’ del lenguaje”)]. 
Excurso: ¿Qué quiere decir “fundamento” de derechos?. — Por ejemplo, véase el planteamiento siguiente: “... la cuestión relativa al concepto y fundamento de los derechos. Se trata, en todo caso, de problemas que están en estrecha relación. En efecto, todo concepto de los derechos presupone una toma de posición sobre su justificación [i.e., fundamentación]: por su parte, toda justificación parte de un concepto previo de los derechos. (...) [U]na toma de postura sobre estas cuestiones ha sido identificada como el modelo dualista... [el cual se asienta en] las cinco claves siguientes, que nos sirven también para dar una primera visión de conjunto del modelo: las tres vertientes del concepto integral de los derechos, la compaginación entre razón e historia, el normativismo corregido, el Estado social y democrático de derecho y la conexión de los derechos con la ética pública. (...) Desde el metafundamento el modelo dualista que aquí se defiende intenta construir las bases justificatorias del discurso de los derechos sin referencia, o si se prefiere con mínimas referencias, a cualquier situación espacial o temporal. Desde el fundamento, el modelo presenta las bases justificatorias del discurso de los derechos pero dentro de una determinada situación espacial y temporal. Como veremos, el metafundamento de los derechos está en el logro de la libertad moral, mientras que el fundamento se situará, tomando como referencia también a la libertad moral, en el logro de la libertad social. (...) Los contenidos y el significado de los derechos exigen la constitución de un sistema democrático exigente caracterizado por la conexión entre derechos. (...) Esta exigencia, junto a aquellas que nos surgieron en el examen del marco moral, y que de forma muy resumida se traducen en la defensa de una idea procedimental de los derechos que caracteriza a estos como instrumentos de libertad que poseen todos los seres humanos en cuanto sujetos morales y que facilitan el logro de planes de vida, constituyen el paradigma dualista de los derecho y por tanto, se presentan como la base que permite comprender y justificar los derechos” (DE ASÍS ROIG, 2001: 5, 11, 24, 89).]

Piénsese como fuere sobre los modos en que se abordan ahí cualesquiera de los contenidos mismos propuestos mediante tal planteamiento, lo cierto es que esa manera de entender la palabra "fundamento" tiende un marco tan desmesuradamente amplio de posibles tipos de referentes por examinar para tales efectos, que entonces prácticamente todo (o casi todo) cuanto sea dable predicar con respecto a derechos es susceptible de ser calificado como asunto propio de tales o cuales "fundamentos" suyos. Si bien tal sentido lingüístico, poco menos que ilimitado, acogido así por ese autor para subsumir ideas de DD.HH. bajo dicho término, no es propiamente incorrecto en cuanto uso idiomático, de todos modos no se ve cómo pueda ello contribuir a aclarar ni poco ni mucho cómo sería dable identificar, iy sobre todo a distinguir bien!, los asuntos en cuestión.

\section{EN CONCLUSIÓN: FÓRMULAS VACÍAS, CUESTIONES DE PALABRAS Y DEMÁS}

Lo cierto es que, y créase o no en unos entes intelectualistas como aquellos subrayados por Robles, al fin de cuentas no se suministra pista alguna para conocer cuáles serían los contenidos específicos que él tomaría en cuenta para ello, y cuáles eventualmente no. Tampoco, menos que menos, ofrece indicaciones para orientarse con vistas a saber cómo determinar sus eventuales modos de incidencia ("conectarla”, "se inserta”) a guisa de "fundamento" para resolver las múltiples discrepancias y diferencias en las aplicaciones reales de los llamados DD.HH.; o para constatar qué "consensos" — ¿en el papel o en la propia conciencia real de los sujetos involucrados? - son los efectivos respectivamente en cada sociedad real. Por último, su punto de vista lo resume así:

\footnotetext{
"Se distingue el fundamento relativo o político de los derechos, que no puede ser otro que el consenso racional, del fundamento absoluto o moral, radicado en la idea de autorrealización personal entendida como realización de un orden de valores” (ubicado en la contrapata de ese libro).
} 
Así topamos, por añadidura, con la fórmula-vacía "racional”, invocada como clave para localizar los "fundamentos" en cuestión. ¿Qué más se puede pedir para confinarlos a reinar, convenientemente inmunizados contra las confrontaciones empíricas, en el pleno limbo de los entia congéneres? [Como puntualiza Albert: “... constituye un auténtico obstáculo en la discusión sobre racionalidad, el hecho de que la palabra 'racional' sea a menudo (aunque no siempre) entendida ante todo como un término valorativo; de modo tal que algunos teóricos tratan de invertir en su concepto de racionalidad todo aquello que consideran bueno, mientras otros temen llamar 'racional' acaso a las conductas de delincuentes, porque estas no armonizan con nuestras exigencias morales".] $]^{22}$.

En síntesis: la cuestión decisiva verdaderamente no es si se prefiera imputar unos u otros significados semánticos generales al término "fundamentar", sino saber de qué maneras específicas sea dable aprehender sus eventuales contenidos precisos en la práctica y qué efectos reales tenga ello mismo -llámesele como se le llame: "fundamentos" o de cualquier otro modo- en las conductas humanas catalogadas así. Solo que, para identificar bien ni más ni menos que eso, las conductas (activas y pasivas en cuestión), hay que empezar por tener claro de QUÉ estamos hablando a ciencia cierta ahí cuando entendemos poder identificar mediante justamente esa palabra, "fundamentos", las realidades sociales en que importe fijarse al respecto así.

Mas no dejo de darme cuenta que mis puntualizaciones sobre los planteamientos del profesor Robles, esbozadas en el presente comentario, son a propósito de unas cuestiones de palabras ${ }^{23}$. En efecto, he procurado indagar a qué se le quiera llamar "fundamentar" los DD.HH., según la manera como presenta él ese asunto. Quiere decir que, si bien se mira, mi pregunta básica no indaga propiamente si en última instancia esos eventuales objetos son reales o imaginarios. (Aun siendo imaginarios podrían ser precisos: p. ej., lo es la noción de sirena, difícilmente suscitará dudas saber si estamos o no estamos ante una de estas mismas cuando tenemos claramente un objeto ante nuestra vista). Este interrogante es de orden netamente epistemológico: ¿̇irve aquello, la elucidación de los susodichos "fundamentos", para localizar esos objetos mismos, vale decir, discernir tales o cuales datos prácticos sustantivos sobre conductas-DD.HH.? Esto es: ¿Cómo saber CUÁLES serían ahí los propios “objetos” psicológico-individuales, o conductual-sociales, o semántico-conceptuales, o ...? (i.e., unos que no sean simplemente sabidos de por sí en el medio correspondiente, sea el social en general u obvios para los juristas allí).

22 Lo «racional». - ALBERT, 1994: 255 (trad. E.P.H.). Sobre la vasta manipulabilidad retórica de las expresiones "racional” y "razonable”, cf.: 2006, Sec. B.I.6 (pp. 97 y ss.: "Múltiples modalidades de 'racionalidad', carácter persuasivo de esa palabra”); 2010c, esp. parte III (pp. 344 y ss.: : “ 'Racionalidad’ como expediente para racionalizaciones escapistas”); 2011, esp. § II.3 (pp. 266 y ss.: “'Racional’, 'razonable', etc.: ¿concepción demasiado ‘estrecha' o es preferible una mucho 'más amplia’? (y el asunto de las “fórmulas vacías’)”). Mi presentación más detallada de la variadísima multivocidad que ofrece la palabra "racionalidad” es: 1988b y 2018d, complementado por 2018a y 2019b.

${ }^{23}$ Cf. VAZ FERREIRA, 1963: 74 y ss. (“Cuestiones de palabras y cuestiones de hecho”). 
Hube de concluir que la gran vaguedad de las etiquetas lingüísticas empleadas por Robles para tal propósito no permiten, salvo sometiéndolas a precisiones que no se encuentran en sus planteamientos (como tampoco, por lo general, en las oratorias políticas o elucidaciones académicas sobre tales materias), saber con nitidez cuáles sean esos "objetos" en sus individualizaciones reales, esto es, siempre que entre los actores sociales se presentan discrepancias sobre su identificación en la práctica. La verdad es que, quiérase o no, los ritos de "fundamentación" acerca de los llamados DD.HH. no se ve que desempeñen sino unas funciones retóricas de adorno al verbalizar soluciones —discutidas o no discutidas - para cuyas determinaciones efectivas es indiferente, en los hechos, que se conozca o no el contenido de tales ejercicios discursivos.

Semejantes expedientes de fundamentación no son sino un sector más entre las variadas armaduras de “obrepciones lógicas” [Kelsen, 1958: 23] construidas ya sea por la dogmática jurídica profesional o en la (meta) Teoría del Derecho. Sin embargo, cuando son tan colosalmente in-determinadas como las justificaciones de esa clase consideradas en el presente examen, o tantas otras por el estilo que circulan en textos académicos, ni siquiera cabe afirmar que ellas serían propiamente falsas, pues los criterios de verdadero-o-falso no están en condiciones de "morder" sino sobre datos de referencia presentados de modo relativamente preciso.

Y lo cierto es que, después de todo, tanto dichas reflexiones de Robles como las observaciones mías ofrecidas aquí, no menos las unas que las otras, por supuesto "no les van ni les vienen” (intellectualist assumption aparte) a los protagonistas corrientes de los discursos-DD.HH... ¡Faltaba más!

\section{LITERATURA}

\section{a) Estudios del autor que conciernen específicamente a la temática-DD.HH.}

HABA, E. P.,

1976: La idea de Totalitarismo y la libertad individual, Autopsia de una noción mistificadora, Pról. León Cortiñas-Peláez, Bogotá, Temis, xxxiv-256 p.

1977: "Derechos humanos, libertades individuales y racionalidad jurídica (Algunas observaciones de orden metodológico)", Revista de Ciencias Jurídicas, Universidad de Costa Rica, núm. 31, pp. 159-180, 1977a. — Este estudio se recoge (con leves modificaciones) en 2012a, t. III: Tema 9, Sec. 1.

1981: “¿Derechos humanos o derecho natural? (Metacrítica de una crítica iusnaturalista a la noción de 'derechos humanos')”, Revista de Ciencias Jurídicas, Universidad de Costa Rica, núm. 45, pp. 105-128, 1981. Publ. también en Anuario de Derechos Humanos, núm. 2 (marzo 1983), pp. 203-229,. — Ese estudio se recoge (con leves modificaciones) en 2012a, t. III: Tema 9, Sec. II. 
1982: “Control sobre las libertades, por medio de 'la' Libertad como ideología”. El texto original se publicó en Memoria del X Congreso Mundial Ordinario de Filosofía del Derecho y Filosofía Social, México, UNAM, vol. VI, pp. 163-183, 1981. Una versión algo ampliada (sus Apéndices I y II) apareció poco después en Revista de Filosofía de la Universidad de Costa Rica, San José (C.R.), vol. XX, núm. 51, pp. 55-69, 1982. — Versión corregida y muy ampliada: 1992.

1984a: "Droits de l'homme, concepts mouvants, idéologies", Archives de Philosophie du Droit, t. 29 (1984), pp. 323-339.

1984b: "Doctrina ideal y doctrina real de la Seguridad Nacional”, en Los derechos humanos y su protección por parte del Estado. Memoria del Primer Congreso Mundial de Derechos Humanos, San José (C.R.), vol. IV, pp. 153-203. [El contenido de la Parte I es igual al de la Parte III de 1984c.]

1984c: "Conceptos indeterminados, derechos humanos y Seguridad Nacional”, Revista de Filosofía de la Universidad de Costa Rica, vol. XXII, núm. 55-56 (1984), pp. 3-30. [También publicado con el título: "Interpretaciones de los derechos humanos. El problema de los conceptos indeterminados y la Doctrina de la Seguridad Nacional, en el Constitucionalismo latinoamericano", Anuario de Derechos Humanos, Madrid, núm.3 (1985), pp. 89-135.. Las Partes I y II de ese estudio pasan a ser desarrolladas de modo mucho más amplio en el cap. III de 1986e; la Parte III coincide con la Parte I de 1984b.]

1985: "Dimensiones constitucionales de los derechos humanos en América Latina: (I) Protección judicial de los derechos humanos”, Revista Judicial, Corte Suprema de Justicia (Costa Rica)), Año X, núm. 35 (dic. 1985), pp. 53-71.

1986a: “Dimensiones constitucionales... : (II) Estados de excepción”, Ibíd., num. 36 (marzo 1986), pp. 81-100.

1986b: “Dimensiones constitucionales... : (III) Libertades de expresión”, Ibíd., núm. 37 (junio 1986), pp. 65-89..

1986c :“Dimensiones constitucionales... : (IV) Derechos económicos”. Ibíd., Año XI, núm. 38 (set. 1986), pp. 79-92.

1986d. :"Dimensiones constitucionales... : (V) Incidencia del Derecho Internacional sobre el Derecho interno”, Ibíd., núm. 39 (dic. 1986), pp. 91-102.

1986e: Tratado básico de derechos humanos, con especial referencia al Derecho Constitucional latinoamericano y al Derecho Internacional. Examen realista-crítico, tomos I (Conceptos Fundamentales) y II (Indicadores Constitucionales), San José (C.R.), Juricentro, xlvi-970 p. [PDF descargable en Internet, sitio USAID]. — Inédito: t. III (Líneas prospectivas, Índices).

1986f: “Interpretación judicial, política y derechos humanos”, Enciclopedia Jurídica Omeba, Apéndice/Tomo V, pp. 434-442, Buenos Aires, Driskill. 
1988a: "Constitución y emergencia (Apuntes en torno al proceso constituyente de Nicaragua)”, Sistema. Revista de Ciencias Sociales, núm. 85 (1988), pp. 109-126. Publicado también en Revista de Ciencias Jurídicas, Universidad de Costa Rica, núm. 63 (mayo-agosto 1989) pp. 21-42.

1992: "Retórica de 'la' Libertad contra las libertades (Control sobre las libertades, por medio de 'la' Libertad como ideología)", Revista de la Facultad de Derecho, Universidad de la República (Uruguay), núm. 2 (enero-junio 1992), pp. 129-167. Publ. también en Revista de Ciencias Jurídicas, Universidad de Costa Rica, núm. 75 (mayoagosto 1993), pp. 113-158.

1993: "Définitions, interprétations et pratique des droits de l'homme. De la 'grammaire' aux 'formes de vie' dans la rhétorique des droits de l'homme”, Revue Internationale de Sémiotique Juridique/International Journal for the Semiotics of Law, vol. VI, núm. 16, pp. 3-44. - Es una exposición corregida y ampliada de las tesis expuestas en el § 11 de 1986e.

1995: "Magia verbal, realidades y sentido fermental de los, así llamados, ‘derechos’ económicos”, Sistema, núm..125 (marzo 1995), pp. 59-74. — Versión revisada en Criterio Jurídico, Pontificia Universidad Javeriana, vol. 4 (2004) pp. 7-30.

2000: “Totalitarismo", en Diccionario Electoral, San José (C.R.), Instituto Interamericano de Derechos Humanos, t. II, pp. 1211-1217.

2003a: "Educación en derechos humanos (Costa Rica)", en colaboración con Hugo Alfonso MUÑOZ QUESADA, Revista de Ciencias Jurídicas, Universidad de Costa Rica, núm. 100 (enero-abril 2003), pp. 25-60.

2003b: “¿De qué viven los que hablan de derechos humanos? (Tres tipos de discursos-DH: ‘de’, 'para’, ‘con’)”, Doxa, núm. 26 (2003), pp. 869-885. — Versión revisada en: Empório do Direito, 15/11/2015 (http://emporiododireito.com.br/backup/?s=Enrique+Haba).

2004a: “Apuntes sobre enseñanza de derechos humanos”, en colaboración con Walter ANTILLÓN MONTEALEGRE, Libro Homenaje al Prof. Walter Antillón, San José (C.R.), pp. 371-375.

2004b: "El asunto del 'fundamento' para los derechos humanos: ipseudoproblema! (o bien, es cuestión de unas elucidaciones cuasiteológicas)”, Doxa, núm. 27, pp. 429-435.

2008: "El lenguaje de los derechos humanos como un 'mal menor' (Anotaciones complementarias sobre la 'practicidad', extra-científica, de los discursos con que se reclaman esos derechos)", Estudios en Homenaje al Profesor Gregorio Peces-Barba, vol. II. Teoría y metodología del derecho, pp. 607-628, Madrid, Dykinson. [Versión revisada en: Criterio Jurídico, vol. 8 (2008), núm. 2, pp. 25-44.] 
2012a: Metodología (realista) del Derecho. Claves para el razonamiento jurídico de visión social práctica, Tomos I y II (xvi-963p.) + III (CD: 951 p.), San José (C.R.), Editorial UCR. [está en preparación una versión revisada de esa obra, será publicada por Ediciones Olejnik en 2019]. Allí: t. III, Tema 9: “Observaciones metodológicas sobre el discurso de los 'derechos humanos' y el recurso al 'derecho natural" ".

2012b: "Sobre unas argumentaciones que extrapolan (non sequitur) datos biológicos hacia lo específicamente normativo”, San José (C.R.), Amicus curiae presentado ante la Corte Interamericana de Derechos Humanos, 12 p. — Versión revisada: 2019a.

2012c: "Zapatero a tus zapatos... De cómo ubicar gato por liebre, a guisa de 'ciencia' '”' (breve presentación de la idea central desarrollada en 2012b), San José (C.R), periódico La Nación, Sec. Opinión, 7-11-2012 (http://www.nacion.com/opinion/foros/Zapatero-zapatos_0_1303869665.html) [texto incluido en 2019a].

2013a: "Puntualizaciones terrenales en torno a las formas de discursear sobre el talismán 'derechos humanos'. Un compendio de observaciones poco complacientes, sobre todo con respecto a ciertas cómodas maneras de hablar mucho y no decir casi nada”; Revista Telemática de Filosofía del Derecho, núm. 17, pp. 3-81.

2016a: Axiología jurídica fundamental. Bases de valoración en el discurso jurídico (Materiales para discernir en forma analítico-realista las claves retóricas de esos discursos), $3^{\mathrm{a}}$ ed. (revisada y nuevamente ampliada), San José (C.R.), Editorial UCR, xxii425 p.. Allí: Secs. C.III (\# 109-128), D.III.2-4 (\# 160-167) y E (\# 166-199).

2019a: "Falacias a propósito de la fertilización in vitro. Sobre unas argumentaciones que extrapolan (¡non sequitur!) datos biológicos hacia lo específicamente normativo"; se publicará en 2019.

\section{b) Otros trabajos del autor referidos}

HABA, E. P.,

1988b: "Rationalité”, en ARNAUD. A.-J. (Ed.), Dictionnaire Encyclopédique de Théorie et de Sociologie du Droit, pp. 337-340, París y Bruselas, Librairie Générale de Droit et de Jurisprudence (LGDJ) \& Story-Scientia. — Versión ampliamente reelaborada: 2018c.

1996a: “Lógica formal y Derecho”; Enciclopedia Jurídica Omeba-Apéndice VII, pp. 625-632, Buenos Aires, Driskill. — Una versión revisada de este estudio se recoge en 2012a, t. III-Tema 10 (pp. 641 y ss.). Presentaciones más breves: 2012a, Sec. D.IV (pp. 499 y ss.: "Lógica deóntica (Su esterelidad como conocimiento y su inocuidad para servir en las prácticas jurídicas efectivas)”); 2015a, cap. IV (pp. 207 y ss.: "Racionalidad mecánica: lógica deóntica”). 
1996b: “Una discusión: ¿Quiénes son los 'irracionalistas’ en la Teoría del Derecho”, Doxa, núm. 19, pp. 385-402. - Versión corregida y ampliada, en: PALOMINO MANCHEGO, J. F. (Dir.), Discusión sobre el carácter anti-científico del Derecho, pp. 271-315 ("Racionalidad e irracionalidad en el Derecho (¿Quiénes son los ‘irracionalistas’?”), Lima, Grijley, 1999. Versión definitiva, nuevamente revisada y ampliada: en 2015a, cap. 3 (pp. 153 y ss.: "Racionalidad e irracionalidad en la ciencia jurídica (¿Quiénes son los ‘irracionales’?”.

1997: "Variantes del pensamiento escapista en una moderna 'Santa Familia': sobre Rawls, Habermas, etcétera (Acerca de la concepción 'misionera' para las ciencias sociales)”, Sistema, núm. 137 (marzo 1997), pp. 109-125, 1997. [Recogido, por partes, en el seno de 2010b.]

1998: “Teorización constructivista como 'forma de vida' (Sobre ‘formas y reglas' del discurso jurídico en los tribunales inexistentes)”, Doxa, núm. 21/vol. I, pp. 147-170 - Versión revisada y ampliada, en 2015a: cap. VI (297 y ss.: "Ciencia jurídica imaginaria. Vocaciones astronáuticas —constructivismo - en la actual Teoría del Derecho, practicadas como “divertimento" académico (y desempeñadas como "forma de vida” profesoral)”).

2000: "Semiótica ilusionista y semiótica desencantadora. Mitomanías de la Razón 'constructivista': ¿ ¿racionalidad de los juristas o racionalidad de los iusemióticos?”, Doxa, núm.23, pp. 561-596.

2006: Metodología jurídica irreverente. Elementos de profilaxis para encarar los discursos jurídicos terrenales, Dykinson, Madrid, 2006, 440 p. — Versión revisada y muy ampliada: 2012a.

2007: “Contra la 'Santa (charla-) Familia'. Anclajes básicos de la vocación astronáutica promovida por Rawls, Habermas y otros apóstoles del wishful thinking académico”, Doxa, núm. 30, pp. 491-524. [los desarrollos que se plantean ahí no son lo presentado en el artículo de 1997].

2009: "El bluff Dworkin. Su rehabilitación del no-saber en la actual Teoría del Derecho (Retorno al realismo ingenuo y apogeo del efecto-Vicente, lanzados por una reencarnación más del Prof. Beale), Criterio Jurídico [http://criteriojuridico.puj.edu.co], vol. 9, 2009-1, pp.155-258. — Una versión abreviada de este estudio se publicó anteriormente en Doxa, núm. 24 (2001), pp. 165-201.

2010a: Los juicios de valor. Elementos básicos de Axiología General. Epistemología del discurso valorativo práctico (Materiales para discernir condiciones de racionalidad en esos discursos), San José (C.R.), Editorial UCR, 2a ed., xxvii-449 p. [versión, nuevamente revisada y aumentada, de la obra que en la misma editorial se había publicado anteriormente llevando entonces como título principal el que actualmente va allí como primer subtítulo.]

2010b: Entre tecnócratas y “wishful thinkers”. La visión misionera de las ciencias sociales, Granada, Comares, $370 \mathrm{p}$. 
2010c: "Razones para no creer en la actual Teoría (ilusionista) de la Argumentación. Papel que tales teorizaciones cumplen como más nueva ideología de legitimación con respecto, especialmente, al discurso jurídico profesional (Observaciones sobre la falaciocidad de ellas como descripción del pensamiento judicial y también acerca de su inocuidad como propuesta práctica para este mismo)”, Doxa, núm. 33, pp. 321-360. — Forma parte (texto revisado) también de 2014, pp. 27-102.

2011: “Debate sobre Teoría de la Argumentación: Avatares de lo 'racional’ y lo 'razonable', cuando son eximidos de tener carnet de identidad (como también sobre unos ecos en Teoría del Derecho de la perenne dicotomía entre 'El científico y el político')”, Revista Telemática de Filosofía del Derecho, núm. 14, pp. 239-316. Forma parte (texto revisado) también de 2014: pp. 201-326 y 387-401.

2013b: "La opción capital para los razonamientos jurídicos: ¿novelas de conceptos o una tecnología social?)”, Doxa, núm. 36, pp. 509-550. — Versión revisada (y algo abreviada) en: 2018b, Segunda Parte, cap. II (pp. 183-234); también en Empório do Direito, 12/11/2015 (http://emporiododireito.com.br/?s=Enrique+Haba).

2014 (Ed.): Un debate sobre las teorías de la argumentación jurídica, LimaBogotá, Palestra-Temis, 2014, 444 p.

2015a: La ciencia de los juristas: ¿qué “ciencia”? De la ciencia jurídica normal a la ciencia jurídica exquisita, San José (C.R.), Editorial Jurídica Continental,. $473 \mathrm{p}$.

2015b: “¿Qué es 'realidad’ jurídica? De cómo aprehenderla en cuanto a los discursos jurídicos”, Revista Telemática de Filosofía del Derecho, núm.18, pp. 67-130.

2016b: "Lógica viva (Vaz Ferreira) como base de pensamiento para contraponer a la hegemonía del 'geometrismo' en la actual Teoría del Derecho”, Alicante, I. Congreso de Filosofía del Derecho para el Mundo Latino (Sección “Argumentación, racionalidad y Derecho”) (http://iusfilosofiamundolatino.ua.es/download/HABAVaz\%20Ferreira\%20[completo].pdf).

2018a: “Atajos para una racionalidad jurídica ilusoria: 'universalidad', ‘consistencia’/'coherencia’, pretensión de 'corrección’, lo 'razonable’, etc. (¿Quiénes son los juristas 'iluminados’?)», Revista Telemática de Filosofía del Derecho, núm. 21, pp. 3-45. [Complemento: 2019b.]

2018b: Invitación al razonamiento jurídico realista. Sus puntos de partida fundamentales más un modelo procedimental heurístico, Lima, Palestra, 319 p.

2018c: “El desafío de Kirchmann a lo ‘académicamente correcto’ para razonar como jurista. Vigencia de un antiguo diagnóstico, más algunas observaciones (que no son simpáticas) sobre la actual Teoría del Derecho", "Estudio liminar" en KIRCHMANN, J. H. v., La jurisprudencia no es ciencia. El carácter a-científico de la llamada ciencia del derecho, pp. 9-109, Argentina, Ediciones Olejnik. [Es la versión un 
tanto reelaborada del estudio original: “Kirchmann sabía menos... ¿pero vio mejor!”, Doxa, núm. 14, 1993, pp. 269-317.]

2018d: “Qué quiere decir 'racional’? (Multiusos de ese término persuasivo)"; Revista de Ciencias Sociales Universidad de Costa Rica, núm. 260, 2018-II, pp. 165189. [Complemento: 2019b.]

2018e: "Puntualizaciones realistas sobre la conceptuación: 'redes’ del derecho. Realidades, silencios y fantasías que se conjugan al postularla como 'paradigma' renovador del pensamiento jurídico”, Doxa, núm. 41, pp. 297-317.

2018f: Anotaciones para no acoplarse al efecto-Vicente (ni sucumbir ante la 'corrección profesoral)"; se publicará en Empório do Direito [es la versión reelaborada de "Entrevista a Enrique P. Haba”, Justiça do Direito, vol. 25-n 1 (Jan-Jun 2001), pp. 155-196, Universidade de Passo Fundo (UPF)-Facultade do Direito].

2019b: “A contravía de ‘lo profesoralmente correcto’ en Teoría del Derecho. Una discusión adyacente con respecto a qué sea 'racional' (Sobre ciertas falacias de inmunización académica dirigidas a sustentar, bajo ese membrete, la idealización profesoral del razonamiento jurídico)”; se publicará en Revista de Ciencias Jurídicas (Universidad de Costa Rica), uno de sus números de 2019.

c) Trabajos pertenecientes a otros autores (mencionados en el presente estudio)

ALBERT, H., 1972: "Modell-Platonismus. Der neoklassische Stil des ökonomischen Denkens in kritischer Beleuchtung” (El platonismo de modelos. El estilo neoclásico del pensamiento económico en iluminación critica), en TOPITSCH, 1972, pp. 406-434.

ALBERT, H., 1973: Tratado sobre la razón crítica, trad. R. Gutiérrez Girardot, Buenos Aires, Sur..

ALBERT, H., 1987: Kritik der reinen Erkenntnislehre. Das Erkenntnisproblem in realistischer Perspektive (Crítica de la teoría pura del conocimiento. El problema del conocimiento en perspectiva realista), Tubinga, J.C.B. Mohr (Paul Siebeck).

ALBERT, H., 1994: Kritik der reinen Hermeneutik. Der Antirealismus und das Problem des Verstehens (Crítica de la hermenéutica pura. El antirrealismo y el problema de la comprensión), Tubinga, J.C.B. Mohr (Paul Siebeck).

ARNOLD, T. W., 1962: The Symbols of Government, Nueva York, Harbinger Book [la ed. or. es de 1935].

ATIENZA, M. y JIMÉNEZ REDONDO, M., 1993: "Entrevista con Stephen E. Toulmin”, trad. M. Jiménez Redondo, Doxa, núm. 13, pp. 329-356. 
BERGER, P. y LUCKMANN, T., 1968: La construcción social de la realidad, trad. S. Zuleta y rev. técn. de M. Giménez Zapiola, Buenos Aires, Amorrortu.

BOBBIO, N., 1962: El problema de la guerra y las vías de la paz, trad. J. Binaghi, Barcelona, Gedisa.

DE ASÍS ROIG, R., 2001: Sobre el concepto y el fundamento de los derechos: una aproximación dualista, Madrid, Dykinson.

DEGENKOLBE, G., 1965: "Über logische Struktur und gesellschaftlichen Funktionen von Leehrformeln" (Sobre estructura lógica y funciones sociales de las fórmulas vacías), Kölner Zeitrschrift für Soziologie und Sozialpsychologie, año 17, pp. 327-338.

KELSEN, H., 1958: ¿Qué es la teoría pura del derecho?, trad. E. Garzón Valdés, Córdoba (Arg.), Universidad Nacional de Córdoba.

KOCH, H.-J., 1977: “Über juristisch-dogmatisches Argumentieren im Staatsrecht” (Sobre argumentación jurístico-dogmática en el Derecho Estatal), en ID. (Ed.), Seminar: Die juristische Methode im Staatsrecht. Über Grenzen von Verfassungs- und Gesetzesbindung (Seminario: El método jurídico en el Derecho Estatal. Sobre los límites de la subordinación a la Constitución y a la ley), Frankfort, Suhrkamp, pp. 13157.

KOLAKOWSKI, L., 1975: La presencia del mito, trad. C. Piechocki, Buenos Aires, Amorrortu.

LLEWELLYN, K. L., 1930: “A Realistic Jurisprudence — The Next Step”; Columbia Law Review, núm. 30, pp. 431-465.

LLEWELLYN, K. L., 1977: Recth, Rechtsleben und Gesellschaft (Derecho, vida del derecho y sociedad), Berlín, Duncker und Humblot [el texto original es de 1931/1932].

MELIZZO, M. 1968: El lenguaje de los políticos, Barcelona, Fontanella.

MOURGEON, J., 1978: Les droits de l'homme, París, Presses Universitaires de France.

OGDEN, C. K. y RICHARDS, I. A., 1954: El significado del significado, trad. E. Prieto, Buenos Aires, Paidós [ed. or. ingl. 1923].

OPP, K.-D., 1970: Methodologie der Sozialwissenschaften. Einführung in Probleme ihrer Theoriebildung (Metodología de las ciencias sociales. Introducción a problemas de elaboración de sus teorías), Hamburgo, Rowohlt.

ROBLES, G., 1992: Los derechos fundamentales y la ética en la sociedad actual, Madrid, Cuadernos Civitas. 

Eudeba.

ROSS, A., 1963: Sobre el derecho y la justicia, trad. G, R. Carrió, Buenos Aires,

SALAS, M. E., 2012: «Sin Derecho ni Razón. Sobre el garantismo penal de L. Ferrajoli: su carencia de validez científica y de practicidad real», Doxa, núm. 35, pp. 751789.

SALAS, M. E., 2017: “Teoria de la argumentación contra el argumentum porci”, en AGUILÓ REGLA, J. y. GRÁNDEZ, P. P (Eds.), Sobre el razonamiento judicial. Una discussion con Manuel Atienza, Lima, Palestra, pp. 329-346.

SAVATER, F., 1989: Panfleto contra el Todo, Madrid, Alianza Editorial.

SOKAL, A. y BRICMONT, J., 1999: Imposturas intelectuales, trad. J. C. Guix Vilaplana y rev. técn. M. Candel, Barcelona, Paidós.

TOPITSCH, E., 1971: Sozialphilosophie zwischen Ideologie und Wissenschaft (Filosofía social, entre ideología y ciencia), Neuwied y Berlín, Luchterhand. [Especialmente: "Die Menschenrechte als Problem der Ideologiekritik" (Los derechos humanos como problema de la crítica a la ideología), pp. 71-96.].

TOPITSCH, E., 1972: "Sprachlogische Probleme der sozialwissenschaftlichen Theoriebildung” (Problemas lógico-lingüísticos de la formación de teorías en las ciencias sociales), en ID. (Ed.), Logik der Sozialwissenschaften (Lógica de las ciencias socials), pp. 17-36, Colonia, Kipenheuer \& Witsch.

TOPTITSCH, E., 1988: Erkenntnis und Illusion. Grundstrukturen unserer Weltauffassung (Conocimiento e ilusión. Estructuras básicas de nuestra concepción del mundo), Tubinga, J.C.B. Mohr (Paul Siebeck).

VAZ FERREIRA, C., 1963: Lógica viva (Adaptación práctica y didáctica), Montevideo, Homenaje de la Cámara de Representantes de la República Oriental del Uruguay, vol. IV [ed. or. 1910]. — Comentario: Haba, 2016b.

WALLAS, G., 1962: Human Nature in Politics, Intr. A. L. ROWSE, Lincoln (USA), University of Nebraska Press [ed. or. 1908].

WELDON, W. T., 1953: The Vocabulary of Politics, Hardmondworth, Penguin Books. 